\title{
Surgical treatment of colonic Crohn's disease: a national snapshot study
}

\author{
SICCR Current status of Crohn's disease surgery collaborative
}

Received: 19 August 2020 / Accepted: 17 November 2020 / Published online: 2 December 2020

(C) The Author(s) 2020, corrected publication 2021

\begin{abstract}
Aim The different surgical options for patients with colonic Crohn's disease (CD) include segmental colectomy, subtotal colectomy or proctocolectomy with end ileostomy. We present a national, multicentre study, promoted by the Italian Society of Colorectal Surgery with the aim to collect benchmark data and national variations on multidisciplinary management and postoperative outcomes of patients undergoing surgery for colonic $\mathrm{CD}$.

Methods All adult patients having elective surgery for colonic CD from June 2018 to May 2019 were eligible for participation in this retrospective study. The primary outcome measure was postoperative morbidity within 30 days of surgery.

Results One hundred twenty-two patients were included: 55 subtotal colectomy, 30 segmental colectomy, 25 proctectomy and 12 proctocolectomy. Eighty-six patients (70.4\%) were discussed at the inflammatory bowel disease (IBD) multidisciplinary team meeting (MDT) prior to surgery. This ranged from $76.6 \%$ for segmental colectomy to $60 \%$ for subtotal colectomy, $66.6 \%$ for proctocolectomy and $48 \%$ for proctectomy. The proportion of patients counselled by a stoma nurse preoperatively was $50 \%$. Laparoscopy was associated with reduced postoperative morbidity $(p=0.017)$ and shorter length of hospital stay $(p<0.001)$, whilst pre-operative anti-TNF was associated with Dindo-Clavien $\geq 3$ complications $(p=0.023)$ and longer in-hospital stay $(p=$ 0.007). The main procedure performed (segmental colectomy, subtotal colectomy, proctocolectomy or proctectomy) was not associated with postoperative morbidity $(p=0.626)$.

Conclusions Surgery for colonic CD has a high rate of postoperative complications. Almost a third of the patients were not preoperatively discussed at the IBD MDT, whilst the use of minimally invasive surgery for surgical treatment of colonic CD ranges from 40 to $66 \%$.
\end{abstract}

Keywords Crohn's disease $\cdot$ Crohn's colitis $\cdot$ Inflammatory bowel disease $\cdot$ Segmental colectomy $\cdot$ Proctocolectomy $\cdot$ National audit

\section{Introduction}

Crohn's disease (CD) is a chronic inflammatory condition that can affect any part of the gastrointestinal system, with one third of the patients having the disease confined to the large bowel [1]. There are different surgical options for patients with colonic CD, including segmental colectomy, subtotal colectomy with ileorectal anastomosis or total proctocolectomy with end

SICCR Current status of Crohn's disease surgery collaborative valeriocelentano@yahoo.it

1 Queen Alexandra Hospital Portsmouth Hospitals NHS Trust, Portsmouth PO6 3LY, UK ileostomy [2]. Surgical treatment of colonic CD can be challenging in view of the high risk of postoperative septic complications [3], the high rate of clinical and surgical recurrence and the impaired functional outcomes and quality of life that can result following extensive surgery. For this particular presentation of $\mathrm{CD}$, a multidisciplinary management is of outmost importance [4], because evidence concerning the ideal surgical strategy is scarce. Moreover, differently from ulcerative colitis, surgical treatment of colonic $\mathrm{CD}$ comprises less extensive alternatives to proctocolectomy.

The most recent guidance on surgical treatment of inflammatory bowel diseases (IBD) of the Association of Coloproctologists of Great Britain and Ireland (ACPGBI) suggested that a segmental or subtotal colectomy and ileorectal 
anastomosis are both viable bowel-preserving options in case of isolated segmental colonic $\mathrm{CD}$ [5]. A recent meta-analysis concluded that segmental, subtotal and proctocolectomy can be equally effective in patients with colonic $\mathrm{CD}$, but the quality of the included studies limits the external validity of the findings [6].

Of note, most studies do not consistently record key performance indicators of CD surgery, with paucity of audits on patient-reported outcome measures (PROMs) [7]. A limited number of studies have focused on postoperative complication in patients with colonic $\mathrm{CD}$ [8] with some being small case series over long period of times, or even before the availability of treatments with biologics $[9,10]$. The aim of this study was to describe the management of colonic CD according to several quality indicators of postoperative outcome in patients included in a nationwide study promoted by the Italian Society of Colorectal Surgery (SICCR).

\section{Methods}

\section{Study settings}

In 2019, the Italian Society of Colorectal Surgery (SICCR) designed the retrospective, multicentre, snapshot study "Current Status of Crohn's disease surgery". The present STROBE [11] compliant study evaluates the treatment of colonic CD in Italy. Details have been previously reported [12]. Briefly, after developing the study protocol, which was approved by the SICCR research board, the steering committee invited Italian colorectal units to join the initiative via an open call and newsletters.

\section{Ethical statement}

Each local principal investigator (PI) was responsible for approval at the local ethical committee, and all participating centres obtained ethical approval. Informed consent was deemed not necessary (retrospective study) from the ethics committees.

\section{Inclusion and exclusion criteria}

All patients (aged 16 or older), who underwent elective surgery for colonic CD from 1 June 2018 to 31 May 2019, were evaluated. The following procedures were included: segmental colectomy, subtotal colectomy, proctocolectomy and proctectomy. If a right hemicolectomy was performed in the context of CD terminal ileitis this was excluded, as were patients having a concomitant segmental left colonic resection in the setting of penetrating ileitis. Patients having surgery for cancer, primary or recurrent $\mathrm{CD}$ of the distal ileum were excluded. The data collection period of 12 months was decided by the steering committee in order to collect a snapshot on the current status of
CD surgery in Italy, to guide targeted quality improvement, where indicated. Patients were considered to have been treated with tumor necrosis factor (TNF)-alpha inhibitors if they had received infliximab infusion within the 4 weeks prior to surgery or adalimumab injection within 2 weeks prior the surgery. Immunosuppressor use was defined as azathioprine or methotrexate within 2 weeks from surgery, whilst an equivalent dose of $20 \mathrm{mg}$ or more of prednisolone within one week of surgery was defined as steroids use.

\section{Study endpoints and outcome measures}

The primary endpoint consisted of postoperative morbidity within 30 days of surgery. Postoperative surgical site infections (SSIs) and use of laparoscopy were the secondary outcome measures.

\section{Data collection and definitions}

Collected data included baseline information and demographics, Montreal classification, preoperative medical treatment, indication for surgery, American Society of Anaesthesiologists (ASA) grade and operative details.

The following were used as key performance indicators:

- Stoma rate, defined as the percentage of patients who received an intestinal stoma (both planned and unplanned, both temporary and definitive);

- Surgical access and conversion rate;

- Length of hospital stay (LOS), defined as duration of the stay from day of surgery to discharge;

- 30-day postoperative morbidity, as any complication occurring during the hospital stay or within 30 days of surgery;

- SSIs within 30 days of surgery, defined as any superficial or deep septic complication related to the surgical site;

- Readmissions and reoperations within 30 days from discharge;

Data on use of PROMs was also collected, as well as preoperative discussion in a dedicated multidisciplinary team meeting (MDT), preoperative consultation with a stoma care nurse and use of total parenteral nutrition (TPN). Data collection was responsibility of the local PI and was performed via the use of prospectively maintained databases, or retrieved using hospital coding registries.

\section{Statistical analysis}

Categorical variables are presented as frequency and percentages and were compared using the chi-square test or Fisher's exact test, as appropriate. Continuous variables are presented as mean ( \pm standard deviation) or median (range) according to their distribution and were compared with the use of Student's 
$t$ test or the Mann-Whitney $U$ test in case of normal or skewed distribution, respectively. Uni- and multivariable logistic regression analyses were run in order to identify variables associated with binary outcomes. Clinically relevant variables with a $p$ value equal to 0.10 or less at the univariate analysis were included in the multiple regression model. The odds ratio (ORs) with a $95 \%$ confidence interval (CI) was estimated as measure of association. All reported $p$ values were two-tailed, and $p$ values of less than 0.05 were considered to be statistically significant. Statistical analysis was performed by using IBM SPSS Statistics for Windows, version 25.0 (IBM Corp., Armonk, NY, USA).

\section{Results}

Overall, 144 patients treated in 20 hospitals were evaluated for inclusion. After excluding 17 patients undergoing urgent or emergency surgery and five patients who had ileostomy formation only, 122 patients were included in the analysis. Out of the included patients, 55 patients underwent subtotal colectomy (45.1\%), 30 segmental colectomy (24.6\%), 25 proctectomy $(20.5 \%)$ and 12 proctocolectomy $(9.8 \%)$. The procedures performed in the segmental colectomy group were as follows: 19 left hemicolectomies, 1 transverse colectomy, 5 Hartmann's procedures and 5 anterior resections. In the subtotal colectomy group, 21 patients received an ileorectal anastomosis $(38.2 \%)$. Every hospital was allocated a unique identifier number (ID). The number of total patients per hospital ranged from one to 32, as shown in Fig. 1. Baseline patients' characteristics and preoperative medical treatments are detailed in Table 1.

\section{Multidisciplinary management and preoperative medical treatment}

Eighty-six patients (70.4\%) were discussed at the IBD MDT prior to surgery. This ranged from $76.6 \%$ for segmental colectomy to $60 \%$ for subtotal colectomy $(p=0.18), 66.6 \%$ for proctocolectomy $(p=0.62)$ and $48 \%$ for completion proctectomy $(p=0.04)$.

The proportion of patients counselled by a stoma nurse preoperatively was $50 \%$ in the segmental colectomy group, compared to $40 \%$ and $50 \%$ of subtotal colectomies and proctocolectomies, respectively. A higher number of patients were assessed by a dietitian and received preoperative TPN in the segmental colectomy group, as shown in Table 1.

\section{Postoperative morbidity and length of stay}

No 30-days post-operative mortality was reported. Overall morbidity within 30 days of surgery is shown in Table 2. Severe complications (Clavien-Dindo $\geq$ III), reoperations and readmissions were slightly more common following segmental colectomy compared to subtotal colectomy (Table 2) but this was not statistically significant. LOS ranged from 8 to 10 days (median 8.5 days, interquartile range $7-13$ ). SSIs were the most common complications, with an incidence ranging from 8 to $27.3 \%$.

A subgroup analysis of the patients receiving an anastomosis without diversion between the segmental colectomy group (10 patients) and subtotal colectomy with ileorectal anastomosis group (19 patients) was performed. This revealed that 5 (50\%) and $8(42.1 \%)$ patients developed postoperative complications in the segmental colectomy and subtotal colectomy group respectively $(p=0.68)$, whilst severe complications (Clavien-Dindo $\geq$ III) occurred in $3(30 \%)$ compared to 1 $(5.2 \%)$ patients in the two groups $(p=0.07)$.

\section{Laparoscopic surgery and conversion rate}

There was no difference in the use of laparoscopic surgery between the included procedures (Table 2). There were no conversions to open surgery in patients undergoing completion proctectomy, whilst for segmental colectomies, subtotal colectomies and proctocolectomies, the conversion rate ranged from 15.8 to $25 \%$.

\section{Patient-reported outcome measures (PROMs)}

There was a low adoption of standardised questionnaires to assess quality of life, bowel, urinary and sexual function following surgery for colonic $\mathrm{CD}$, as these assessments were performed only in 5 patients (4\%).

\section{Univariate and multivariate analysis}

At multivariate analysis, a laparoscopic approach (Table 3) was associated with reduced postoperative morbidity $(p=0.017)$ and shorter LOS $(p<0.001)$, whilst pre-operative administration of anti-TNF correlated with Dindo-Clavien $\geq$ III postoperative complications $(p=0.023)$ and longer LOS $(p=0.007)$. The use of preoperative TPN and anti-TNF was associated with postoperative SSIs at univariate analysis (Table 4). Surgery for recurrent $C D$ was associated with conversion from a laparoscopic to an open approach $(p=0.029)$ and to SSIs $(p=0.042)$. The main procedure performed (segmental colectomy, subtotal colectomy, proctocolectomy or proctectomy) was not associated with postoperative morbidity $(p=0.626)$ or SSIs $(p=0.322)$.

\section{Discussion}

Our study confirms that surgery for colonic CD is affected by high postoperative morbidity, ranging from 36 to $41.8 \%$, with SSIs representing the most frequent complication. Our study 
Table 1 Characteristics of the included patients

\begin{tabular}{|c|c|c|c|c|c|}
\hline & $\begin{array}{l}\text { Segmental } \\
\text { colectomy }\end{array}$ & $\begin{array}{l}\text { Subtotal } \\
\text { colectomy }\end{array}$ & Proctocolectomy & Proctectomy & $p$ \\
\hline Patients & 30 & 55 & 12 & 25 & \\
\hline M:F & $14: 16$ & $23: 32$ & $7: 5$ & $12: 13$ & 0.761 \\
\hline Age & $47(28-79)$ & $39(17-83)$ & $50(24-76)$ & $47(22-77)$ & $0.163^{\dagger}$ \\
\hline BMI & $22(16-27)$ & $21(14-30)$ & $24(15.4-30)$ & $24.5(18-38)$ & $0.006^{\dagger}$ \\
\hline Recurrent disease & $15(50 \%)$ & $24(43.6 \%)$ & $8(66.6 \%)$ & $20(80 \%)$ & 0.017 \\
\hline \multirow{3}{*}{$\begin{array}{l}\text { Montreal classification } \\
\text { A }\end{array}$} & A1 $11(36.7 \%)$ & A1 $11(20 \%)$ & A1 $2(16.6 \%)$ & A1 $1(4 \%)$ & 0.009 \\
\hline & A2 $12(40 \%)$ & A2 $27(49.1 \%)$ & A2 $2(16.6 \%)$ & A2 $8(8 \%)$ & \\
\hline & A3 $7(23.3 \%)$ & A3 $17(30.9 \%)$ & A3 $8(66.6 \%)$ & A3 $14(56 \%)$ & \\
\hline \multirow{2}{*}{$\begin{array}{l}\text { Montreal classification } \\
\text { L }\end{array}$} & L2 $19(63.3 \%)$ & L2 $30(54.5 \%)$ & L2 $4(33.3 \%)$ & L2 17(68\%) & 0.136 \\
\hline & L3 $11(36.7 \%)$ & L3 $25(45.5 \%)$ & L3 $8(66.6 \%)$ & L3 $8(32 \%)$ & \\
\hline \multirow{3}{*}{$\begin{array}{l}\text { Montreal classification } \\
\text { B }\end{array}$} & B1 $3(10 \%)$ & B1 $17(30.9 \%)$ & B1 $3(25 \%)$ & B1 $10(40 \%)$ & 0.429 \\
\hline & B2 $18(60 \%)$ & B2 $25(45.5 \%)$ & B2 $5(41.7 \%)$ & B2 $7(28 \%)$ & \\
\hline & B3 $9(30 \%)$ & B3 $13(23.6 \%)$ & B3 $4(33.3 \%)$ & B3 $8(32 \%)$ & \\
\hline Perianal disease & $16(53.3 \%)$ & $23(41.8 \%)$ & $8(66.6 \%)$ & $18(72 \%)$ & 0.231 \\
\hline $\begin{array}{l}\text { Previous abdominal } \\
\text { surgery }\end{array}$ & $16(53.3 \%)$ & $29(52.7 \%)$ & $6(50 \%)$ & $24(96 \%)$ & 0.001 \\
\hline MDT & $23(76.6 \%)$ & $33(60 \%)$ & $8(66.6 \%)$ & $12(48 \%)$ & 0.169 \\
\hline USS & $17(56.6 \%)$ & $29(52.7 \%)$ & $4(33.3 \%)$ & $8(32 \%)$ & 0.173 \\
\hline MRI & $21(70 \%)$ & $35(63.6 \%)$ & $7(58.3 \%)$ & $19(76 \%)$ & 0.538 \\
\hline $\mathrm{CT}$ & $24(80 \%)$ & $23(41.8 \%)$ & $7(58.3 \%)$ & $8(32 \%)$ & $<0.001$ \\
\hline Capsule & 0 & $1(1.8 \%)$ & 0 & 0 & 0.746 \\
\hline Stoma nurse & $15(50 \%)$ & $22(40 \%)$ & $6(50 \%)$ & $9(36 \%)$ & 0.674 \\
\hline Dietitian & $15(50 \%)$ & $17(30.9 \%)$ & $2(16.6 \%)$ & $2(8 \%)$ & 0.042 \\
\hline TPN & $7(23.3 \%)$ & $8(14.5 \%)$ & $2(16.6 \%)$ & $2(8 \%)$ & 0.433 \\
\hline Steroids & $11(36.6 \%)$ & $27(49.1 \%)$ & $4(33.3 \%)$ & $4(16 \%)$ & 0.043 \\
\hline Immunosupp & $3(10 \%)$ & $7(12.7 \%)$ & $2(16.6 \%)$ & $2(8 \%)$ & 0.858 \\
\hline Anti-TNF & $9(30 \%)$ & $16(29.1 \%)$ & 0 & $1(4 \%)$ & 0.010 \\
\hline
\end{tabular}

$M$ male, $F$ female, $B M I$ body mass index, Montreal classification $A$ age at diagnosis, $L$ location, $B$ phenotype, $M D T$ multidisciplinary team; USS ultrasound, MRI magnetic resonance imaging, $C T$ computed tomography, TPN total parenteral nutrition, $T N F$ tumor necrosis factor

$p$ values are from Pearson's chi square and from ${ }^{\dagger}$ one-way ANOVA reported that approximately one-third of the patients undergoing segmental colectomy were on anti-TNF treatment, whilst up to half of the subtotal colectomies were currently on steroids. We found that anti-TNF treatment was associated with longer LOS and with severe postoperative morbidity (DindoClavien $\geq 3$ ), likely reflecting a selected group of patients compromised or with more complex disease, adding to the literature debate on the effect of biologics on surgical morbidity $[13,14]$. Conversely, we did not demonstrate an increased complication rate for segmental resection compared to subtotal colectomy and proctocolectomy, which is considered to be up to a 2-fold increase as reported in a recent meta-analysis [6]. It is concerning that almost $30 \%$ of the patients did not receive preoperative input from the wider IBD MDT, with preoperative discussion ranging from $76 \%$ for segmental colectomies to $40 \%$ for proctectomies. Moreover, as surgical stoma was a common outcome of surgery for colonic CD (it was performed in 93 patients, $76.2 \%$ ), it should be mandatory for patients to be counselled preoperatively by a dedicated stoma care team, whilst this only took place for 36 to $50 \%$ of the patients. Similarly, preoperative optimisation with TPN and input from the dietitians was more frequent in patients undergoing segmental resections. Prompt planning of elective surgery and high volume IBD surgeons may impact on bowel sparing surgery, preoperative medical treatment and postoperative outcomes when surgery is performed in specialist referral centres, with support from dedicated teams. Rather than expressing a particular preference for one surgical approach over the others, our results highlight the need for careful patient selection, preoperative optimisation and multidisciplinary input, to individualise the treatment according to extent of disease but also patients' expectations and performance status, 
Fig. 1 Number of surgical resections performed for colonic Crohn's disease in the 20 participating hospitals

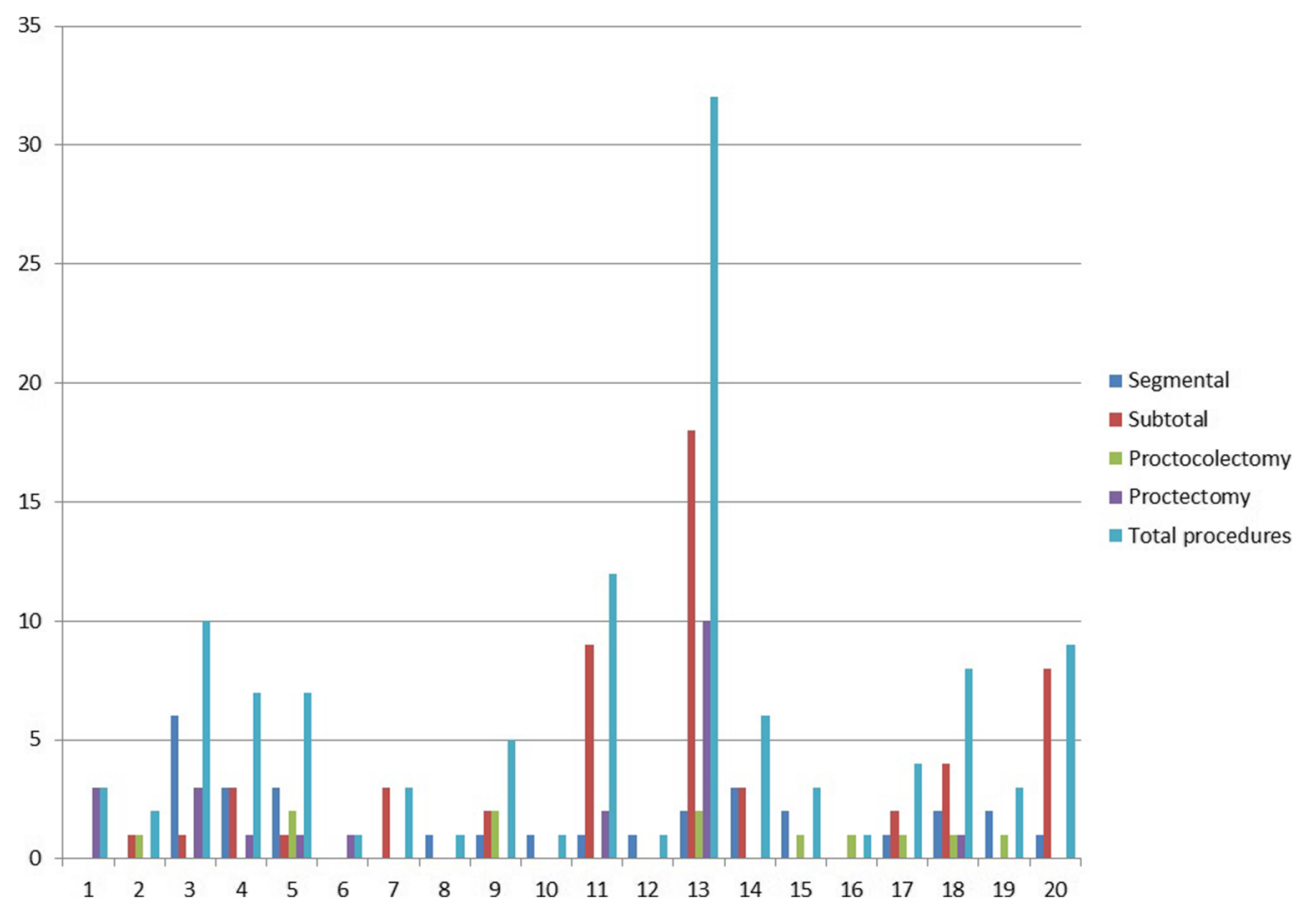

considering the high risk of postoperative complications and the known high recurrence rate of up to $65 \%$ for segmental resections [15].

We collected data on patients undergoing surgery during a 12 months period between 2018 and 2019 obtaining an up to date snapshot of the current status of surgery for colonic CD in Italy. Our results confirm the advantages of a minimally invasive approach for surgical treatment of colonic CD in terms of reduced postoperative morbidity and shorted LOS. However, we found a relatively low use of laparoscopic surgery, which ranged from 44 to $66 \%$ with a considerable conversion rate up to $25 \%$.

Our study demonstrated significant heterogeneity across the 20 participating Italian hospitals in the number of cases performed per year, with 11 hospitals (55\%) performing less than five procedures during the 12 months recruitment period. Rectal resection in CD can be particularly difficult in view of adhesions, inflammation and chronic pelvic abscesses, with possible implications on postoperative functional outcomes such as genitourinary function [16]. Of the 16 hospitals performing at least one procedure between completion proctectomy and proctocolectomy, only four (25\%) performed at least three procedures per year, which could also reflect on the difficulties for surgeons in training to accumulate exposure to these complex procedures [17]. To reduce this variability, the SICCR recently published a national position statement with the aim to standardise multidisciplinary management and surgical treatment of CD nationally [18], and

Table 2 Surgical outcomes

\begin{tabular}{llllll}
\hline & Segmental colectomy & Subtotal colectomy & Proctocolectomy & Proctectomy & $p$ \\
\hline Patients & 30 & 55 & 12 & 25 & \\
Stoma made & $20(66.6 \%)$ & $36(65.4 \%)$ & $12(100 \%)$ & $25(100 \%)$ & 0.004 \\
Lap approach & $19(63.3 \%)$ & $34(61.8 \%)$ & $8(66.6 \%)$ & $11(44 \%)$ & 0.586 \\
Conversion & $3(15.8 \%)$ & $7(20.6 \%)$ & $2(25 \%)$ & 0 & 0.205 \\
LOS & $10(4-34)$ & $8(4-66)$ & $10(4-26)$ & $9(2-34)$ & $0.750^{\dagger}$ \\
Morbidity & $11(36.6 \%)$ & $23(41.8 \%)$ & $5(41.6 \%)$ & $9(36 \%)$ & 0.416 \\
SSIs & $7(23.3 \%)$ & $15(27.3 \%)$ & $3(25 \%)$ & $2(8 \%)$ & 0.281 \\
Dindo $\geq 3$ & $4(13.3 \%)$ & $4(7.3 \%)$ & $1(8.3 \%)$ & $2(8 \%)$ & 0.902 \\
Reoperations & $4(13.3 \%)$ & $2(3.6 \%)$ & $1(8.3 \%)$ & $2(8 \%)$ & 0.055 \\
Readmissions & $4(13.3 \%)$ & $1(1.8 \%)$ & 0 & 0 & 0.520 \\
\hline
\end{tabular}

LOS length of stay, SSIs surgical site infections, Lap laparoscopy

${ }^{\dagger} p$ from one-way ANOVA 
Table 3 Univariate and multivariate analysis for postoperative morbidity in patients with colonic Crohn's disease

\begin{tabular}{|c|c|c|c|c|c|c|}
\hline \multicolumn{7}{|l|}{ Postoperative morbidity } \\
\hline \multirow[b]{2}{*}{ Variable } & \multicolumn{3}{|c|}{ Univariate analysis } & \multicolumn{3}{|c|}{ Multivariate analysis } \\
\hline & OR & $95 \% \mathrm{CI}$ & $p$ & OR & $95 \% \mathrm{CI}$ & $p$ \\
\hline Age & 1.016 & $0.992-1.04$ & 0.193 & & & \\
\hline Sex (female) & 0.663 & $0.318-1.375$ & 0.271 & & & \\
\hline BMI & 0.948 & $0.866-1.032$ & 0.229 & & & \\
\hline ASA grade $\geq 3$ & 1.883 & $0.808-4.425$ & 0.142 & & & \\
\hline Recurrent CD & 1.256 & $0.605-2.635$ & 0.542 & & & \\
\hline Main procedure & 1.072 & $0.812-1.419$ & 0.626 & & & \\
\hline Montreal B = 3 & 2.045 & $0.919-4.591$ & 0.080 & 1.357 & $0.527-3.490$ & 0.527 \\
\hline Montreal L = 3 & 0.560 & $0.259-1.186$ & 0.134 & & & \\
\hline Perianal disease & 0.927 & $0.454-1.888$ & 0.834 & & & \\
\hline Preoperative steroids & 0.794 & $0.368-1.68$ & 0.551 & & & \\
\hline Preoperative immunosuppression & 3.138 & $1.011-10.838$ & 0.054 & 2.825 & $0.652-12.246$ & 0.165 \\
\hline Preoperative anti-TNF & 3.150 & $1.302-7.952$ & 0.012 & 2.967 & $0.944-9.323$ & 0.063 \\
\hline Preoperative TPN & 1.127 & $0.405-3.029$ & 0.813 & & & \\
\hline Access (minimally invasive) & 0.382 & $0.180-0.809$ & 0.012 & 0.344 & $0.144-0.826$ & 0.017 \\
\hline
\end{tabular}

$B M I$ body mass index, $A S A$ American Society of Anaesthesiologists, $O R$ odds ratio, $C I$ confidence interval, $T N F$ tumor necrosis factor, $T P N$ total parenteral nutrition guidelines of several international societies have been released to optimize CD outcomes (e.g. European Crohn's Colitis Organisation-ECCO [19], the American Society of Colorectal Surgery-ASCRS) [20]. A general aim of guidelines is to reduce variations in practice, by providing evidence based guidance on the best treatment options, with the aim to enhance patients' outcomes.

Our study is limited by the small sample size, which may have underpowered the statistical analysis, and retrospective design with an intrinsic risk of recall and information bias.
Table 4 Univariate and multivariate analysis for postoperative surgical site infections (SSIs) in patients with colonic Crohn's disease

\begin{tabular}{|c|c|c|c|c|c|c|}
\hline \multicolumn{7}{|l|}{ Postoperative SSIs } \\
\hline \multirow[b]{2}{*}{ Variable } & \multicolumn{3}{|c|}{ Univariate analysis } & \multicolumn{3}{|c|}{ Multivariate analysis } \\
\hline & OR & $95 \% \mathrm{CI}$ & $p$ & OR & $95 \% \mathrm{CI}$ & $p$ \\
\hline Age & 0.99 & $0.97-1.02$ & 0.613 & & & \\
\hline Sex (female) & 1.31 & $0.55-3.18$ & 0.543 & & & \\
\hline BMI & 1.00 & $0.91-1.10$ & 0.959 & & & \\
\hline ASA grade $\geq 3$ & 1.44 & $0.53-3.69$ & 0.453 & & & \\
\hline Recurrent CD & 2.92 & $1.17-8.03$ & 0.027 & 3.07 & $1.04-9.05$ & 0.042 \\
\hline Main procedure & 0.85 & $0.61-1.17$ & 0.322 & & & \\
\hline Montreal B = 3 & 1.98 & $0.79-4.84$ & 0.137 & & & \\
\hline Montreal L = 3 & 1.34 & $0.56-3.19$ & 0.501 & & & \\
\hline Perianal disease & 1.01 & $0.44-2.34$ & 0.983 & & & \\
\hline Preoperative steroids & 0.92 & $0.37-2.19$ & 0.844 & & & \\
\hline Preoperative immunosuppression & 4.35 & $1.35-14.12$ & 0.013 & 2.06 & $0.48-8.92$ & 0.333 \\
\hline Preoperative anti-TNF & 3.62 & $1.40-9.38$ & 0.008 & 2.55 & $0.76-8.54$ & 0.129 \\
\hline Preoperative TPN & 4.20 & $1.48-11.96$ & 0.007 & 2.95 & $0.91-9.60$ & 0.072 \\
\hline Access (minimally invasive) & 0.66 & $0.28-1.55$ & 0.339 & & & \\
\hline
\end{tabular}

$B M I$ body mass index, $A S A$ American Society of Anaesthesiologists, $O R$ odds ratio, $C I$ confidence interval, $T N F$ tumor necrosis factor, $T P N$ total parenteral nutrition 
Many of the participating centres only included a small number of patients and SSIs and complication rates were directly reported by the operating surgeon, with variability in definitions [21] and high likelihood of selection bias. Moreover, our study focused on short term outcomes of surgery for colonic $\mathrm{CD}$, without evaluating long term surgical recurrence, which should be the focus of prospective studies including mandatory PROMs evaluation.

\section{Conclusions}

Surgery for CD of the colon has a high rate of postoperative complications, which was associated with preoperative antiTNF treatment in our study. Up to $30 \%$ of the patients with colonic CD did not receive input from the IBD MDT, whilst the use of minimally invasive surgery for surgical treatment of colonic $\mathrm{CD}$ ranges from 40 to $66 \%$ despite being beneficial for patients with a shorter LOS and reduced morbidity.

Supplementary Information The online version contains supplementary material available at https://doi.org/10.1007/s00423-020-02038-z.

Funding No funding was received for the study.

\section{Compliance with ethical standards}

Conflict of interest The authors declare that they have no conflict of interest.

Ethics statement The study was approved by the ethics committee of every participating centre, and patients' consent was obtained where required.

Open Access This article is licensed under a Creative Commons Attribution 4.0 International License, which permits use, sharing, adaptation, distribution and reproduction in any medium or format, as long as you give appropriate credit to the original author(s) and the source, provide a link to the Creative Commons licence, and indicate if changes were made. The images or other third party material in this article are included in the article's Creative Commons licence, unless indicated otherwise in a credit line to the material. If material is not included in the article's Creative Commons licence and your intended use is not permitted by statutory regulation or exceeds the permitted use, you will need to obtain permission directly from the copyright holder. To view a copy of this licence, visit http://creativecommons.org/licenses/by/4.0/.

\section{References}

1. Heriot A, Smart P (2019) Current status of segmental colectomy in select Crohn's disease patients. Clin Colon Rectal Surg 32(4):249254

2. Lightner AL (2018) Segmental resection versus total proctocolectomy for Crohn's colitis: what is the best operation in the setting of medically refractory disease or dysplasia? Inflamm Bowel Dis 24(3):532-538. https://doi.org/10.1093/ibd/izx064
3. Ghoneima AS, Flashman K, Dawe V, Baldwin E, Celentano V (2019) High risk of septic complications following surgery for Crohn's disease in patients with preoperative anaemia, hypoalbuminemia and high CRP. Int J Color Dis 34(12):2185-2188

4. Pellino G, Keller DS, Sampietro GM, Annese V, Carvello M, Celentano V, Coco C, Colombo F, Cracco N, Di Candido F, Franceschi M, Laureti S, Mattioli G, Pio L, Sciaudone G, Sica G, Villanacci V, Zinicola R, Leone S, Danese S, Spinelli A, Delaini G, Selvaggi F, The Italian Society of Colorectal Surgery (SICCR) (2020) Inflammatory bowel disease (IBD) position statement of the Italian Society of Colorectal Surgery (SICCR): general principles of IBD management. Tech Coloproctol 24(2):105-126. https:// doi.org/10.1007/s10151-019-02145-0

5. Brown SR, Fearnhead NS, Faiz OD, Abercrombie JF, Acheson AG, Arnott RG, Clark SK, Clifford S, Davies RJ, Davies MM, Douie WJP, Dunlop MG, Epstein JC, Evans MD, George BD, Guy RJ, Hargest R, Hawthorne AB, Hill J, Hughes GW, Limdi JK, Maxwell-Armstrong CA, O’Connell PR, Pinkney TD, Pipe J, Sagar PM, Singh B, Soop M, Terry H, Torkington J, Verjee A, Walsh CJ, Warusavitarne JH, Williams AB, Williams GL, Wilson RG, ACPGBI IBD Surgery Consensus Collaboration (2018) The Association of Coloproctology of Great Britain and Ireland consensus guidelines in surgery for inflammatory bowel disease. Colorectal Dis 20(Suppl 8):3-117

6. Angriman I, Pirozzolo G, Bardini R, Cavallin F, Castoro C, Scarpa M (2017) A systematic review of segmental vs subtotal colectomy and subtotal colectomy vs total proctocolectomy for colonic Crohn's disease. Color Dis 19:e279-e287

7. Morar PS, Hollingshead J, Bemelman W, Sevdalis N, Pinkney T, Wilson G, Dunlop M, Davies RJ, Guy R, Fearnhead N, Brown S, Warusavitarne J, Edwards C, Faiz O (2017) Establishing key performance indicators [KPIs] and their importance for the surgical management of inflammatory bowel disease-results from a panEuropean Delphi consensus study. J Crohns Colitis 11(11):13621368. https://doi.org/10.1093/ecco-jcc/jjx099

8. Iesalnieks I, Spinelli A, Frasson M, Di Candido F, Scheef B, Horesh N, Iborra M, Schlitt HJ, El-Hussuna A (2018) Risk of postoperative morbidity in patients having bowel resection for colonic Crohn's disease. Tech Coloproctol 22(12):947-953. https:// doi.org/10.1007/s10151-018-1904-0

9. Sanfey H, Bayless TM, Cameron JL (1984) Crohn's disease of the colon. Is there a role for limited resection? Am J Surg 147:38-42

10. Andersson P, Olaison G, Hallböök O, Sjödahl R (2002) Segmental resection or subtotal colectomy in Crohn's colitis? Dis Colon Rectum 45:47-53

11. von Elm E, Altman DG, Egger M, Pocock SJ, Gøtzsche PC, Vandenbroucke JP; STROBE Initiative. The Strengthening the Reporting of Observational Studies in Epidemiology (STROBE) statement: guidelines for reporting observational studies. J Clin Epidemiol 2008;61(4):344-349

12. SICCR Current Status of Crohn's Disease Surgery Collaborative (2020) National variations in perioperative assessment and surgical management of Crohn's disease: a multicentre study. Colorectal Dis https://doi.org/10.1111/codi.15334

13. Yamamoto T, Teixeira FV, Saad-Hossne R, Kotze PG, Danese S (2019) Anti-TNF and postoperative complications in abdominal Crohn's disease surgery. Curr Drug Targets 20(13):1339-1348

14. Open Source Research Collaborating Group (\#OpenSourceResearch), Biological treatment and the potential risk of adverse postoperative outcome in patients with inflammatory bowel disease: an open-source expert panel review of the current literature and future perspectives, Crohn's \& Colitis 360, Volume 1, Issue 3, October 2019, otz021

15. Martel P, Betton PO, Gallot D, Malafosse M (2002) Crohn's colitis: experience with segmental resections; results in a series of 84 patients. J Am Coll Surg 194:448-453 
16. Gklavas A, Kyprianou C, Exarchos G, Metaxa L, Dellis A, Papaconstantinou I (2019) Sexual function after proctectomy in patients with inflammatory bowel disease: a prospective study. Turk J Gastroenterol 30(11):943-950

17. Celentano V, Flashman KG (2019) Stepwise training in laparoscopic surgery for complex ileocolonic Crohn's disease: analysis of 127 training episodes. J Surg Educ 76(5):1364-1369. https://doi.org/10. 1016/j.jsurg.2019.03.009

18. Pellino G, Keller DS, Sampietro GM, Angriman I, Carvello M, Celentano V, Colombo F, Di Candido F, Laureti S, Luglio G, Poggioli G, Rottoli M, Scaringi S, Sciaudone G, Sica G, Sofo L, Leone S, Danese S, Spinelli A, Delaini G, Selvaggi F, Italian Society of Colorectal Surgery SICCR (2020) Inflammatory bowel disease position statement of the Italian Society of Colorectal Surgery (SICCR): Crohn's disease. Tech Coloproctol. https://doi. org/10.1007/s10151-020-02183-Z

19. Adamina M, Bonovas S, Raine T, Spinelli A, Warusavitarne J, Armuzzi A, Bachmann O, Bager P, Biancone L, Bokemeyer B, Bossuyt P, Burisch J, Collins P, Doherty G, El-Hussuna A, Ellul P, Fiorino G, Frei-Lanter C, Furfaro F, Gingert C, Gionchetti P, Gisbert JP, Gomollon F, González Lorenzo M, Gordon H, Hlavaty T, Juillerat P, Katsanos K, Kopylov U, Krustins E, Kucharzik T, Lytras T, Maaser C, Magro F, Marshall JK, Myrelid
P, Pellino G, Rosa I, Sabino J, Savarino E, Stassen L, Torres J, Uzzan M, Vavricka S, Verstockt B, Zmora O (2020) ECCO guidelines on therapeutics in Crohn's Disease: surgical treatment. J Crohns Colitis 14(2):155-168. https://doi.org/10.1093/ecco-jcc/ jjz187

20. Strong S, Steele SR, Boutrous M, Bordineau L, Chun J, Stewart DB, Vogel J, Rafferty JF (2015) Clinical Practice Guidelines Committee of the American Society of Colon and Rectal Surgeons. Clinical practice guideline for the surgical management of Crohn's disease. Dis Colon Rectum 58(11):1021-1036. https:// doi.org/10.1097/DCR.0000000000000450

21. Berríos-Torres SI, Umscheid CA, Bratzler DW, Leas B, Stone EC, Kelz RR, Reinke CE, Morgan S, Solomkin JS, Mazuski JE, Dellinger EP, Itani KMF, Berbari EF, Segreti J, Parvizi J, Blanchard J, Allen G, Kluytmans JAJW, Donlan R, Schecter WP, Healthcare Infection Control Practices Advisory Committee (2017) Centers for Disease Control and Prevention Guideline for the Prevention of Surgical Site Infection, 2017. JAMA Surg 152(8): 784-791

Publisher's note Springer Nature remains neutral with regard to jurisdictional claims in published maps and institutional affiliations. 